\title{
The Role of the Institution and Teachers in Supporting Learning ${ }^{1}$
}

\author{
Graham Welch (UCL) and Adam Ockelford (Roehampton)
}

\begin{abstract}
We draw on four contrasting examples to illustrate how institutions and teachers support and shape music learning. Institutions include cultural settings and educational establishments, and teachers are broadly defined as people who have a role in musical learning, such as peers, and are distinguished by having knowledge of perceived value to the learner. The underlying conceptualization is that individual and collective music learning is nurtured within social contexts. The lens of activity theory is used to explore how learning and development are the product of inter- and intrapersonal behaviors shaped by cultural artifacts, tools (e.g., language, selected music repertoire), expectations and "rules" (conventions and norms) within a community setting. The examples reflect the contextualized music learning experiences of (1) a young musical savant, (2) advanced music students in higher education, (3) female choristers in a traditionally allmale UK cathedral setting and (4) diverse groups of adolescents in lower secondary school.
\end{abstract}

1. Published as: Welch, G. F. \& Ockelford, A. (2016). The Role of the Institution and Teachers in Supporting Learning. In S. Hallam, I. Cross, \& M. Thaut (Eds.), The Oxford Handbook of Music Psychology, Second Edition. (pp. 509-526). Oxford: Oxford University Press. ISBN: 9780198722946 [Chapter 32] 


\section{Keywords:}

music, learning, institutions, teachers, activity theory, savant, adolescents, students

\section{Introduction}

Musical behavior and development are natural byproducts of the interface between intrapersonal maturational processes and an individual's enculturation into locally dominant sound worlds (e.g., Hallam and Lamont, 2004; Welch, 2001, 2006a; Barrett, 2011) and are basic to human design. They are not dependent on the input of an institution or a "teacher" as such, but are related to the evolution of generative skills in a sonic environment — our natural propensity to "continually create, recreate and develop new ideas and materials" (Hallam and Lamont, 2004, p. 243). Within such environments, there are various "institutions" (including cultural settings as well as educational establishments) and "teachers," i.e., people who have a role in musical learning, with both exemplified in the peer-to-peer popular music skill development of musicians and adolescents (Green, 2001; Tarrant, North and Hargreaves, 2002). Other examples are found in the interweaving of indigenous musics with the rituals of daily life, such as in the iorram or rowing songs of the Isle of Mull (Macnab, 1970) and as practiced by the Northern Ewe children of Eastern Ghana:

6.00 a.m. The day's work has begun in earnest. In one home, girls are pounding dried cassava in a mortar to make kokonte. In another, they are pounding recently harvested rice in order to remove the husks. As with other forms of daily pounding ... the work ... is made a little less routine by incorporating some rhythmic interest. In place of a regularly spaced 
alternation between two pounders . . . a variant may be introduced.

Pounder 1 keeps a steady pace while Pounder 2 pushes her strokes closer

to Pounder 1's. Here as elsewhere in Northern Ewe culture, work merges

into play and reemerges into work.

(Agawu, 1995, p. 12)

Contemporary explanations of the mechanism for the process of learning in social and cultural settings often draw on the work of Vygotsky, Luria, and Leont'ev from the first half of the twentieth century (cf. Cole, 1999; Kaptelinin, 2014), as well as being related to systems theory (the interlinking of relationships within some form of organizationvon Bertalanffy, 1968) and social ecology theory (the nurturing of development within social contexts-Bronfenbrenner, 1979). The early Russian investigators and those who developed their work subsequently (such as the Finnish researcher, Engeström) explored how learning and development are the product of inter- and intrapersonal behaviors that are shaped by cultural artifacts (e.g., literature), alongside tools (including psychological tools, e.g., language and other symbol systems), expectations, "rules"/conventions and norms. The internalization of artifacts is also seen to facilitate the agency of the individual, such that the artifacts themselves are modified through personal use, enabling the possibility of consequent change within the culture. Thus there is an ongoing mediation process in how individuals interact with the world around them and make sense of their reality.

-----insert Figure 1 about here--- 
A key concept in this view of culturally based learning is "activity" which has been defined as "the engagement of a subject toward a certain goal or objective" (Ryder, 2005). One widely cited model of activity within a system is provided by Engeström (1999, 2001—see Figure 1). In his interrelated system of elements as applied to education, the "subject" (the learner) is supported in reaching the "object" (the intended learning outcome) through interaction with various "mediating artifacts" (such as language and other symbol systems), a conceptualization strongly associated with the work of Vygotsky. This process is seen as being embedded in a social context that provides support for the activity through the subject and intended outcome being located within a "community" that has "rules" (expectations for behavior) and also the likelihood of a "division of labour" (diversity of effort). Because of the possibility of tensions within the activity system, it may be that the actual "outcome" is at variance with the intended "object" (i.e., that there are unintended outcomes - as explored below).

If the activity system is seen in relation to learning within an institution (such as a school or social collective, e.g., the family) in which certain people either adopt or are expected to have roles as "teachers," then it is possible to envisage how the theorized activity system might be able to support the intended learning in music (or fail to). The world of music has certain characteristics:

- $\quad$ There are many different musical genres and subgenres. 
- $\quad$ Each has its own customary view of what counts as musical learning, or at least the outcomes of musical learning in relation to performance, as well as the traditions (custom and practice) in how learning is usually fostered in relation to the genre's characteristic features, as illustrated in the "institutions" of India (e.g., the tradition of musical "households" or Gharanas; Farrell, 2001) and Japan (e.g., the "culture schools" managed by major business and voluntary organizations; Murao and Wilkins, 2001).

- In many diverse musics, there is evidence of the high status accorded to the accomplished expert who demonstrates solo mastery over the sonic material.

- $\quad$ Certain cultures, such as China, Afghanistan, and India, continue to have strong traditional music genres. These are characterized by expertise transmission within families across several (or many) generations (Jones, 1995; Doubleday and Baily, 1995; Farrell, 1997). In such traditional cultures, the "teacher" is in a master/apprentice relationship with the “pupil” within a strong local community, often fostered by pupils playing for each other in the presence of the master.

Aspects of the role of institutions and teachers in the process by which musical expertise is learned and demonstrated are illustrated in the four examples that follow (see below). The first relates to musical development in a special education context, the second to advanced music learning in higher education, the third to the relatively new music 
education world of the female cathedral chorister, and the fourth to pupils' experiences of lower secondary school classrooms in England. In the first three cases, the intention is to suggest how the teacher and institution support the "activity" of learning within a social context, whilst the last demonstrates that not all music learning within an institution is necessarily positive or as intended.

\section{The Role of Institutions and Teachers in Supporting Musical Learning: Four Examples}

\section{Example 1: Supporting Musical Learning in a young Prodigious Musical Savant}

Derek Paravicini is a musical savant, now approaching his mid-thirties, who is well known to the public through success on the concert platform as a jazz and popular pianist on both sides of the Atlantic. His early life was very difficult, and the initial development of his musical expertise was highly unconventional (Ockelford, 2007).

Derek was born premature at 26 weeks, weighing a little over $700 \mathrm{~g}$. In the fight for survival that followed, he lost his sight through retinopathy of prematurity, and developed unspecified neurological impairments that meant he grew up with severe learning difficulties. His family was upper class and employed the services of an experienced nanny to care for him and oversee his upbringing. Neither she, nor anyone else, expected Derek to develop musically in a way that was at all out of the ordinary (there was no history of exceptional musical development in the family). However, following the diagnosis of Derek's blindness, a few weeks after returning home from 
hospital, Nanny decided that sound was likely to play an important part in his life. So she sang to him constantly and surrounded him with sound-making toys. And just like any other baby's environment, Derek's day-to-day life was perfused with music from the TV, radio, and other incidental sources.

Derek was attracted to music as a potential source of stimulation and order in the world around him, and unbeknown to Nanny or his family, his ability to process musical sounds developed rapidly and precociously. Desperate to find an activity that would keep the 1-year-old Derek gainfully occupied, Nanny gave him his grandfather's little electric keyboard to play with. From the start, Derek loved the sounds that it produced and discovered that he could imitate some of the musical sounds with which he had come into contact. With no intervention on the part of Nanny or his family, and with no visual model to guide him, Derek taught himself how to get his hands and fingers in the right places at the right times to recreate some of the snatches of melody and harmony that were familiar to him. This situation-Stage 1 in the journey of Derek's musical learning —is summarized in terms of Engeström's model in Figure 2.

-----insert Figure 2 about here---

One day, after about six months of self-directed exploration at the keyboard, Nanny heard Derek play a version of the Irish folksong "Cockles and Mussels"- - using both hands, with a tune and rudimentary accompaniment. His repertoire soon widened, and Derek's relationship with Nanny, his extended family, and friends took a new course with the addition of this unexpected but welcome dimension. Still there was no formal 
intervention or guidance from those around Derek in terms of supporting his learning. And in the months and years that followed, Derek continued to chart his own, unique, autodidactic course (Stage 2: Figure 3).

-----insert Figure 3 about here---

At the age of 5, Derek came to the attention of the second author (AO), who was then teaching in a school for the blind in southwest London. Derek's raw talent was evident, as were his technical eccentricities - including the use of his knuckles, hands, and even the occasional judicious dip of his nose which enabled him to reproduce sonorities that were beyond the reach of his limited span (around a fifth on the standardsized keyboard). In AO’s view, while Derek's achievements up to that point were remarkable, particularly given his blindness and severe developmental delay, it was essential that he should come to accept the intervention of another, to guide his further musical development and realize his creative intent. However, Derek had never experienced anything approaching a conventional "teacher-pupil" relationship, and he was not remotely inclined even to share his piano with anyone else, let alone engage in a structured learner-teacher dyad. Hence, a large part of AO's effort for the first six months of working with Derek was directed towards showing him that interaction through music could be productive and, above all, enjoyable. And gradually, involving an initial degree of physical intervention, Derek did come to appreciate that discourse through the medium of musical improvisation was possible and could indeed be a source of great pleasure. 
Engaging in social discourse through sound alone could not solve Derek's technical challenges, however, and a final stage in AO's early relationship with him was necessary, whereby Derek would allow AO to show him_-physically_-how to hold his hands and use his fingers in conventional patterns that would facilitate his technical development. Clearly, Derek had no concept of the goals that AO was pursuing, so it was critical that he enjoyed being guided through the daily ritual of technical exercises, scales, and arpeggios that AO devised for him. Luckily, Derek relished the one-to-one attention and the orderliness of his practice routine, and the pattern of highly formalized intervention with AO continued throughout his childhood on a daily basis (Stage 3: Figure 4).

-----insert Figure 4 about here---

There is much to learn from Derek's story: most obviously, the fact that an individual can be motivated to pursue musical learning to a highly advanced level at an early age with no direct intervention or encouragement on the part of others, and with no global sense of moving toward the goal of becoming a competent performer (see also Ockelford, 2008; Ockelford, Pring, Welch and Treffert, 2006; Ockelford, 2013). Beyond this, however, it is also the case that Derek, as someone with severe learning difficulties, could, initially through a discourse comprising nothing but musical sounds, develop a relatively conventional teacher-pupil relationship that eventually enabled him as an adult to have a career as an internationally recognized musician. 


\section{Example 2: Supporting Musical Learning in Higher Education}

Higher education (HE), on the other hand, is a relatively (often highly) selective educational environment that seeks to advance already competent musical skill levels in young people who normally exhibit (or report) little or no disability (though see, for example, Lerner and Straus, 2006).

Within the spectrum of HE in music, there are observable similarities and differences in the way that the activity of music learning is processed. These are particularly related to context, such as the age and gender of performers, their principal musical genre and the particular HE location. For example, a recent study of advanced music learning and teaching in four UK Higher Education Institutions (HEIs) investigated how classical, popular, jazz, and Scottish traditional musicians deepened and developed their learning about performance in undergraduate, postgraduate, and wider music community contexts (Welch, Duffy, Whyton and Potter, 2008; Papageorgi and Welch, 2015). In the first year of the study, a specially designed, web-based questionnaire was used to survey 244 musicians across the four participant HEIs. In addition to demographic information, participants provided self-reports about their earliest engagement with music (including first instrumental or vocal lessons), secondary and tertiary education, as well as significant musical experiences and influences. The participants were questioned about the perceived relevance of a range of musical skills and activities, experience of performance and general life anxiety, how they spent their time in an average week, the pleasure that they derived from engagement in musical activities, various self-views (musical self-efficacy, self-esteem, self-regulation), group membership and their beliefs about the nature of expertise in musical performance and teaching. 
The resultant data analyses suggest that all musicians attached great importance to achieving a high overall standard of performance, although they had different perspectives on the processes by which this might be achieved (Creech et al., 2008). For example, in terms of the performance expectations of their particular musical "community" and its requisite "tools" and "rules" (pace Engeström), classical musicians ranked the ability to improvise as the least important musical skill, but perceived sightreading to be very important. In contrast, in relation to the performance expectations of their particular communities, the other-than-classical musicians (jazz, popular, Scottish traditional) tended to assign the least importance to the ability to sight-read, but placed greater emphasis on playing from memory and improvisation. Although all musicians recognized the value of practice, the community of classical musicians tended to place greater emphasis on practicing alone, whereas other-than-classical musicians attached greater relevance to making music for fun, networking, and extracurricular activities such as listening to a diverse range of musics and engaging in professional conversations with peers (see Figure 5). Nevertheless, both classical and other-than-classical groups considered musical expertise to involve the possession of global musical skills that could be transferred to other musical genres (Papageorgi et al., 2010).

-----insert Figure 5 about here---

An exploration of underlying processes that might explain the similarities and differences between these two groups implicated both institutions (whether home, school, or elsewhere) and teachers (including parents, private tutors, and teachers in educational 
institutions). Other-than-classical musicians reported that they typically began to engage with music of any kind at a later age than their classical musician peers (other-thanclassical: $M=8.4$ years, classical: $M=6.6$ years). Similarly, they began formal learning on their first instrument at a later age (other-than-classical: $M=12$ years, classical: $M=$ 8.8 years). Notwithstanding the nature of their early musical experiences, all the participant musicians, irrespective of genre, were able to achieve the requisite baseline skill levels for entry to higher education and beyond. Nevertheless, contexts were not identical. Classical musicians reported that their most important musical influences (past and present) were parents, instrumental/vocal teachers, significant musical events, professional colleagues, and previous membership of county (regional) music ensembles. In contrast, other-than-classical musicians claimed to be particularly influenced by wellknown performers, as well as university or college lecturers and informal groups of friends (Creech et al., 2008). Across all musicians, irrespective of genre, higher education tutors (whether lecturers in particular aspects of music or specialist solo instrumental and vocal teachers) were reported to be significant agents in a communal process of advanced music learning (Creech and Papageorgi, 2015).

Overall, participant classical musicians rated themselves higher in terms of perceived musical expertise. The basis for this difference is likely to relate to (1) the comparative longevity of classical musical cultures in higher education, (2) other aspects of participants' group-based self-views, and (3) differences in participants' cumulative years of study. For example, interviews with senior academics in the participant HEIs revealed that: 
1 Classical music had been established for much longer in their academic programmes compared to the three selected other-than-classical genres (jazz, popular, and Scottish traditional). Concomitantly, classical music teaching and learning and assessment practices were reported to be more firmly embedded, rehearsed, formalized, and understood within their particular communities.

2 It may be that (as reported earlier) other-than-classical musicians have idealized views of expertise that relate to how they see themselves in comparison to the individual quality of "star" performers in their chosen genre rather than some more generic HE measure of performance.

3 It is also the case that the participant musicians in "other-than-classical" genres typically begin to engage with music at a later age and, as a consequence, were more likely to have expert role models from outside their peers and teachers, having had relatively less time to be immersed in their musical genre.

As an example of differences within a musical genre in relation to age and experience, the same data set suggests that portfolio career classical musicians who engage in both performance and teaching are more likely to be able to identify successful teaching strategies than their younger, undergraduate peers. Furthermore, the activity of teaching, allied to extensive solo performance experiences, is likely to reduce levels of performance anxiety (Papageorgi, Creech and Welch, 2013). 


\section{Example 3: Supporting Female Music Learning in a UK Cathedral Setting}

Male choristers have participated in UK cathedrals since their inception in 597 AD at Canterbury. In comparison, it was not until 1991 that Salisbury became the first old UK cathedral foundation to admit girls on the same basis as boys. The political impact and success of their initiative (although foreshadowed by other religious institutions earlier in the twentieth century but without the same publicity) has led to a growing (and perhaps less grudging) acceptance of female choristers within the previously all-male culture. By 2006, a majority of cathedrals had choristers of both sexes for the first time in their long history, even though it continues to be relatively rare for the two sexes to sing together, other than at special festival events (Welch, 2007, 2011).

One of the cited reasons for the longevity of the all-male cathedral music tradition was that young females were regarded as being unable to sing with the same "pure" quality of vocal timbre as demonstrated by the young male voice in the performance of the cathedral sacred music repertoire. This belief does have some basis in the physical realities of child voice acoustics, even though research has demonstrated its fallibility. First, there are slight differences in the relative sizes of girls' and boys' vocal anatomy (the male being slightly larger throughout childhood and into adolescence-cf. Welch and Howard, 2002) and these could be expected to generate perceptible disparities in acoustic outputs. Second, with regard to untrained children's voices, there is increasingly perceptible psycho-acoustic differentiation between the sexes as they progress through childhood (Sergeant, Sjölander and Welch, 2005; Sergeant and Welch, 2008, 2009), with observable gender-related differences in their sung spectra. However, the power of the musical activity system in the cathedral is such that formal induction of girls into its 
performance expectations can generate changes in their basic vocal behavior so that any gender differences are reduced significantly and often become imperceptible. A series of perceptual studies from the mid 1990s onwards has demonstrated that membership of a cathedral choir can allow girls to be trained to produce sounds that are "boy-like" in character in order to match the customary, male-biased, performance expectations of the musical repertoire (Sergeant and Welch, 1997; Howard and Welch, 2002; Welch, 2006c; Welch and Howard, 2002).

Detailed longitudinal case study data from one cathedral suggests that the activity of becoming a female chorister is closely linked to the customary tripartite relationship in music (Small, 1999) between the physical setting, people (performers and listeners), and the way that the musical soundscape constrains the variety of possible musical outcomes. The induction process for both young males and females involves the novice chorister (“probationer") being required to learn, practice, rehearse, and perform music systematically many times each week across the school and ecclesiastical year, whilst standing between and listening to the vocal models of established senior performers ("Head Chorister," "Deputy Head Chorister," "Senior Corner Girls”), supported by group-based (communal) teaching by a highly experienced church musician ("Organist and Choir Director" or "Deputy"), in order to master a ritualized repertoire (such as the Introit, Psalms, Response Settings, and Anthem for "Evensong") that involves both choral and solo performance (see Figure 6 for how this experience can be framed within an activity system-Welch, 2007, 2011).

-----insert Figure 6 about here--- 
The acoustic features of the rehearsal and performance spaces within the chancel and choir of the cathedral also shape the learning experience, with features of the choristers' sound amplified by the high stone vaulting of the nave and adjacent spaces and fed back to the performers. The collective and ritual nature of the performance is reinforced by the addition of adult male voices (for most services) and the organ. It is not surprising, therefore, that females are able to perform the established religious repertoire in customary fashion, given the interrelated and situated expectations of the musical learning process and the longevity of the performance practices within the culture that are handed down across generations of cathedral musicians (and where it is extremely rare for a new director of music to be appointed from outside the tradition).

\section{Example 4: Supporting Music Learning in the Lower Secondary School}

In contrast to the above, it is possible that institutions and teachers can also hinder as well as support learning in music. For example, notwithstanding a general rise in the reported quality of music education in English schools since the turn of the millennium according to Ofsted ${ }^{1}$ — the independent schools inspection body (e.g., Ofsted, 2009, 2012) — there is often a notable disparity in the individual experiences of pupils (Welch, 2006b; Zeserson et al., 2014). In particular, music teaching in the lower secondary school classroom (ages 12-14) has often been reported as less successful generally than the overall quality in the other school-age phases (both older and younger). The reasons for these systematic differences are likely to relate to:

1 The organization of the timetable in primary schools where one class teacher tends to take all curriculum subjects and therefore is in a better 
position to know each individual child across a school year and to match music teaching to individual need.

2 English National Curriculum music learning expectations of primary school children are less (in terms of the complexity of musical behaviors) than in secondary schools; this may encourage more positive judgments from primary school inspectors (who are themselves unlikely to be primary music specialists).

3 Upper secondary school music (ages 14-16) is optional, catering for a small minority of pupils (between 7-9\%) who have opted to study music for a further two years to examination at age 16.

4 Lower secondary school music is compulsory for all pupils - a period of intense personal development in their musical identity (Tarrant, North and Hargreaves, 2002).

Nevertheless, some secondary schools have been able to counter this trend, even in contexts where "success" in school examinations may not be the norm. For example, an analysis of data from secondary schools in one part of inner London with a high Black African-Caribbean (BAC) population found that up to $62 \%$ of such pupils were opting to study music (with an average across schools of $24 \%$ ). This was much higher than the non-BAC groups in the same schools (average 8\%; Spence, 2006). Furthermore, these pupils went on to achieve higher grades in their $16+$ examinations for music than in their other subjects, such as English, mathematics, and science. A recurrent theme from interviews with these young people was that lesson content had greater enjoyment when it drew on music that they knew, liked, and/or could play. They also reported greater 
liking of teachers who showed respect for them and their music. Such positive emotional engagement appears to be reflected in their relative success in school music.

Further insights in why some young people are "successful" at school music and some are not were reported in a recent study of lower secondary school music (Saunders, 2006). Pupils in the final year of compulsory music education in England (school Year 9, age $13+$ ) have to make a decision about whether or not to continue their school music studies. Coding and analyses of the transcripts of interviews with 44 pupils in one school revealed that pupils tended to see themselves in one of five categories (see Table 1).

-----insert Table1 about here---

Only one of the five groups is fully engaged with school music (termed the "traditional Western musician"), in part because of their formal instrumental performance skills and an ability to identify successfully with the content of the school music curriculum. However, four other groups of pupils have alternative, less positive perspectives. Some see themselves as "nonmusicians"; some have self-taught instrumental skills, but do not identify with school music, even though they are accomplished musicians (“alternative Western musician”); some are accomplished musicians in a traditional sense, but believe that "school music" is irrelevant and a possible threat to their "musician" status ("disengaged traditional Western musician"); and some find that the mismatch between their musical skills and the skills needed for the school curriculum is intimidating to their self-concept as a musician ("disengaged alternative Western musician"). When interviewed, a significant number of young people 
consider themselves (wrongly) to be unsuitable for continuing music studies. Yet virtually all connect successfully with music outside school, as consumers, listeners, and/or practitioners. Unless pupils identify and find success with school music (e.g., Spence, 2006), they are likely to disengage. Subsequent research and analyses of pupil interviews in three other schools confirmed these findings (Saunders, 2008). Comments from individual pupils demonstrated the kinds of diversity in their experiences of music in school:

“it's my favourite lesson of the whole week and well, I wish we could do a bit more of it really."

"I think the stuff at lunchtimes and for the shows is really good, but that lessons aren't anywhere near as exciting as that. I suppose that's because we can't all sing and play like them though."

"Music at school is pants; it's just not any good. It's all duff music. I mean, who listens to this stuff?"

"I'm learning from my brother and his mate taught him, so when we get together, it's a bit scrappy, but we're getting better. I don't do it that much in class 'cos Miss wants us working on the keyboards and I'm not great at that."

Collectively, these comments illustrate the underlying positive connection that these young people have with music, although not necessarily the kinds of music (and musical 
practices) found in school (see Saunders and Welch, 2012, for an example of positive adolescent engagement with music in a non-formal setting). Adolescence is a period characterized by the emergence of strong musical identities (Zillman and Gan, 1997), often with a clear perception of boundaries between different musics as young people use music to negotiate positions for themselves within their group identities (O'Neill and Green, 2001). It is not surprising, therefore, that school music has such a mixed reception during this age phase.

\section{Conclusion}

Overall, the various examples cited above are an indication of how learning and teaching in music are shaped by processes outside the individual, not least because of the influences of group membership (allied to age and gender), performance expectations and practices, and professional and institutional cultures. Indeed, there are a growing number of initiatives internationally that are exploring the institution-based learning of a Western classical music instrument as a force for social change. These include Sistema-type programmes, including multi-age and whole-school initiatives, such as the In Harmony programme in England (http://ihse.org.uk) and Every Child a Musician in Newham, East London (Welch, Saunders and Himonides, 2014). There are now estimated to be at least 277 similar programmes in 58 countries worldwide (Creech, Gonzalex-Moreno, Lorenzino and Waitman, 2013). In each case, the process of individual induction into the characteristics of a particular musical culture by teachers and institutions influences the formation of identities in music (cf. MacDonald, Hargreaves and Miell, 2002), for better or for worse, at least in terms of dominant models within the culture. Indeed, the 
development of music teachers themselves can be seen within an activity system, i.e., the teacher's understanding of their role is developed both by informal personal reflection of the experience of performance and their own learning, and, more systematically, through their own induction processes by attendance at a specialist pedagogically focused institution.

\section{References}

Agawu, K. (1995). African rhythm. Cambridge: Cambridge University Press.

Barrett, M.S. (2011) (Ed.). A cultural psychology of music education. Oxford: Oxford University Press. von Bertalanffy, L. (1968) General System theory: Foundations, Development, Applications. New York: George Braziller.

Bronfenbrenner, U. (1979). The ecology of human development: experiments by nature and design. Cambridge, MA: Harvard University Press.

Cole. M. (1999). Cultural psychology: some general principles and a concrete example. In Y. Engeström, R. Miettinen and R.-L. Punamäki (Eds.), Perspectives on activity theory (pp. 87-106). Cambridge: Cambridge University Press.

Creech, A., Gonzalez-Moreno, P., Lorenzino, L. and Waitman, G. (2013). El Sistema and Sistema-Inspired Programmes. San Diego: Sistema Global.

Creech, A., Papageorgi, I., Duffy, C., Morton, F., Haddon, L., Potter, J., de Bezenac, C., . . Welch, G.F. (2008). Investigating musical performance: commonality and diversity amongst classical and otherthan-classicalmusicians. Music Education Research, 10(2), 215-234.

Creech, A. and Papageorgi, I. (2015). Concepts of ideal musicians and teachers: ideal selves and possible selves. In I. Papageorgi and G.F. Welch (Eds.), Advanced musical performance: investigations in higher education learning. (pp. 99-114). Farnham: Ashgate.

Doubleday, V. and Baily, J. (1995). Patterns of musical development among children in Afghanistan. In E.J. Fernea (Ed.), Children in the Muslim Middle East (pp. 431-444). Austin: University of Texas Press.

Engeström, Y. (1999). Activity theory and individual and social transformation. In Y. Engeström, R. Miettinen and R.-L. Punamäki (Eds.), Perspectives on activity theory (pp. 19-38). Cambridge: Cambridge University Press.

Engeström, Y. (2001). Expansive learning at work: toward an activity-theoretical reconceptualisation. With a commentary by Michael Young. Learning Group, Occasional Paper No 1. London: Institute of Education. 
Farrell, G. (1997). Indian music and the West. Oxford: Clarendon Press.

Farrell, G. (2001). India. In D.J. Hargreaves and A.C. North (Eds.), Musical development and learning: the international perspective (pp. 56-72). London: Continuum.

Green, L. (2001). How popular musicians learn. Aldershot: Ashgate.

Hallam, S. and Lamont, A. (2004). Learners: their characteristics and development. Psychology of Music, $32(3), 243-252$.

Howard, D.M. and Welch, G.F. (2002). Female chorister development: a longitudinal study at Wells, UK. Bulletin of the Council for Research in Music Education, 153(4), 63-70.

Jones, S. (1995). Folk music of China: living instrumental traditions. Oxford: Clarendon Press.

Kaptelinin, V. (2014): Activity Theory. In: Soegaard, M., and Dam, R.F. (Eds.). The Encyclopedia of Human-Computer Interaction, 2nd Ed.. Aarhus, Denmark: The Interaction Design Foundation. Available online at https://www.interaction-design.org/encyclopedia/activity_theory.html

Lerner, N. and Straus, J.N. (Eds.). (2006). Sounding off: theorizing disability in music. New York: Routledge.

MacDonald, R., Hargreaves, D.J. and Miell, D. (Eds.) (2002). Musical identities. Oxford: Oxford University Press.

Macnab, P.A. (1970). The Isle of Mull. Newton Abbot: David \& Charles.

Murao, T. and Wilkins, B. (2001). Japan. In D.J. Hargreaves and A.C. North (Eds.), Musical development and learning: the international perspective (pp. 87-101). London: Continuum.

Ockelford, A., Pring, L., Welch, G.F. and Treffert, D. (2006). Focus on music: exploring the musical interests and abilities of blind and partially-sighted children with septo-optic dysplasia. London: Institute of Education/RNIB.

Ockelford, A. (2007). In the key of genius: the extraordinary life of Derek Paravicini. London: Hutchinson.

Ockelford, A. (2008). Music for Children and Young People with Complex Needs, Oxford: Oxford University Press.

Ockelford, A. (2013). Music, language and autism: exceptional strategies for exceptional minds. London: Jessica Kingsley.

Ofsted (2009). Making more of music: an evaluation of music in schools 2005-08. Manchester: Ofsted.

Ofsted (2012). Music in schools: wider still, and wider. Manchester: Ofsted.

O’Neill, S. and Green, L. (2001). Social groups and learning in music education. In BERA Music Education Review Group, Mapping Music Education Research in the UK (pp. 26-31). Macclesfield: British Educational Research Association.

Papageorgi, I., Creech, A., Duffy, C., Potter, J., Whyton, T., Morton, F., Haddon, L., de Bezenac, C., Himonides, E. and Welch, G.F. (2010). Perceptions and predictions of expertise in advanced musical learners. Psychology of Music, 38(1), 31-66.

Papageorgi, I., Creech, A. and Welch, G.F. (2013). Perceived performance anxiety in advanced musicians specialising in different musical genres. Psychology of Music, 41(1), 18-41. 
Papageorgi, I. and Welch, G.F. (2015). How do musicians develop their learning about performance. In I. Papageorgi and G.F. Welch (Eds.), Advanced Musical Performance: Investigations in Higher Education Learning. (pp. 169-185). Farnham: Ashgate.

Ryder, M. (2005) What is activity theory? Retrieved from http://carbon.cudenver.edu/ mryder/itc_data/act_dff.html

Saunders, J. (2006). Music learning in year 9: the pupils' perspective. NAME Magazine, 18, 9-11.

Saunders, J. (2008). Pupils and their engagement in secondary school music (unpublished PhD thesis.) Institute of Education, London.

Saunders, J. and Welch, G.F. (2012). Communities of music education. London: Youth Music/International Music Education Research Centre, Institute of Education. http://www.youthmusic.org.uk/what-wedo/our-research/communities-of-music-education.html

Sergeant, D.C. and Welch, G.F. (1997). Perceived similarities and differences in the singing of trained children's choirs. Choir Schools Today, 11, 9-10.

Sergeant, D.C., Sjölander, P.J. and Welch, G.F. (2005). Listeners' identification of gender differences in children's singing. Research Studies in Music Education, 24, 28-39.

Sergeant, D.C. and Welch, G.F. (2008). Age-related changes in long-term average spectra of children's voices. Journal of Voice, 22(6), 658-670.

Sergeant, D.C. and Welch, G.F. (2009). Gender differences in long-term average spectra of children's singing voices. Journal of Voice, 23(3), 319-336.

Small, C. (1999). Musicking - the meanings of performing and listening. A lecture. Music Education Research, 1(1), 9-21.

Spence, S. (2006). Black Caribbean children and school music: expectation and Achievement. NAME Magazine, 18, 12-15.

Tarrant, M., North, A.C. and Hargreaves, D.J. (2002). Youth identity and music. In R. MacDonald, D.J. Hargreaves and D. Miell (Eds.), Musical Identities (pp. 134-150). Oxford: Oxford University Press.

Welch, G.F. (2001). The misunderstanding of music. London: Institute of Education, University of London.

Welch, G.F. and Howard, D.M. (2002). Gendered voice in the cathedral choir. Psychology of Music, 30, $102-120$

Welch, G.F. (2006a). The musical development and education of young children. In B. Spodek and O. Saracho (Eds.), Handbook of Research on the Education of Young Children (pp. 251-267). Mahwah, NJ: Lawrence Erlbaum Associates.

Welch, G.F. (2006b). What research into music teacher education tells us about the contexts and challenges for teacher education. Proceedings, Beijing International Forum on Music Education 2006 (pp. 8497). NAMM/CSME/ISME/CNU, Beijing. (Chinese version, pp. 98-113.)

Welch, G.F. (2006c). Singing and vocal development. In G. McPherson (Ed.), The Child as musician: $a$ handbook of musical development (pp. 311-329). New York: Oxford University Press. 
Welch, G.F. (2007). Addressing the multifaceted nature of music education: an activity theory research perspective. Research Studies in Music Education, 28, 23-38.

Welch, G.F., Duffy, C., Whyton, A. and Potter, J. (2008). Investigating musical performance [imp]: comparative studies in advanced musical learning. ESRC End of Award Report [RES-139-250101].

Welch, G.F. (2011). Culture and gender in a cathedral music context: an activity theory exploration. In M. Barrett (Ed.), A Cultural Psychology of Music Education (pp. 225-258). New York: Oxford University Press.

Welch, G.F., Saunders, J. and Himonides, E. (2014). An evaluation of children's instrumental learning in the Every Child a Musician (ECaM) programme. Proceedings (pp. 321-335). 25th International Seminar on Research in Music Education, Federal University of Paraiba, Brazil.

Zeserson, K., Welch, G.F., Burn, S., Saunders, J. and Himonides, E. (2014). Inspiring music for all: next steps in innovation, improvement and integration. London: Paul Hamlyn Foundation.

Zillman, D. and Gan, S. (1997). Musical taste in adolescence. In D. J. Hargreaves and A. C. North (Eds.), The Social Psychology of Music (pp. 161-187). Oxford: Oxford University Press. 


\section{Figure 1}

The structure of a human activity system.

Reproduced from Y. Engeström, Expansive learning at work: toward an activity-theoretical

reconceptualisation. With a commentary by Michael Young, p. 136 (C) 2001, Institute of Education.

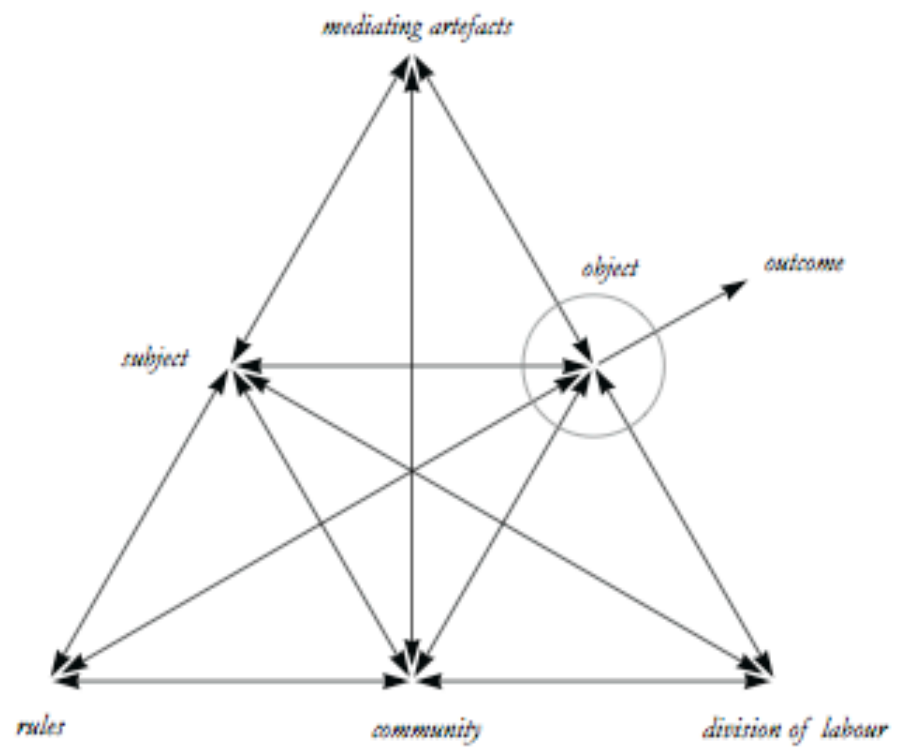


Figure 2: The activity system pertaining to Derek's musical life, 0-15 months

\section{Stage 1 (0-21 months)}

Derek's capacity to process musical sounds and structure develop precociously, and starts to learn to play by ear without the awareness of those around him

mediuting artefucts

- Tapes of music of a range of genres

- Nanny singing nursery rhymes, other songs and hymns

- Music in the wider environment - 'TV, radio, ete

- Derek's grandfather's little electric keyboard

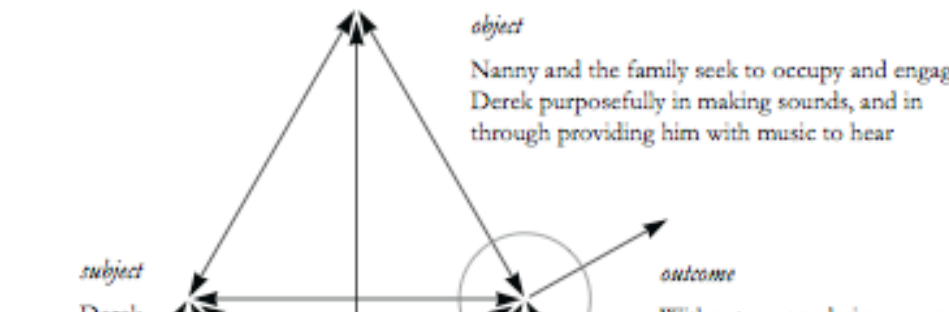

Without anyone being aware of it, Derek's capacity process musical sounds and structure develop precociously, and he starts to develop the capacity to reproduce what he hears on the little keyboard provided for him

miles, atsumptions, expectations and driters

- There are no formal rules operating in relation to Derek's learning to process musical sound

- Nanny 2ssumes that, 25 a blind child, Derek should be stimulated with sound, including music

- Unable to grasp many everyday concepts and given the semantic nature of language, Derek is attracted to the rule-bound, self-referencing nature of musical sounds, for which his blindness and learning difficulties do not present a barrier for him to be able to process

- With regard to his grandfather's keyboard, he is driven purely by the internal motivation of realising that he can reproduce in sound what he hears, and relishing that ability

- Derek is unaware of the assumptions and expectations of those around him 
Figure 3: The activity system pertaining to Derek's musical life, 15-21 months

\section{Stage 2 (21-66 months)}

Derek develops his ability to play the keyboard with the awareness and encouragement of those around him

modiating artefinets

- Derek's grandfather's little electric kerboard

- Subsequently, his father's Yamaha organ and a piano

- Tapes of music in a range of styles, including some that

are chosen deliberately for him to emulate

- Nanny's singing

- Other music in the wider environment
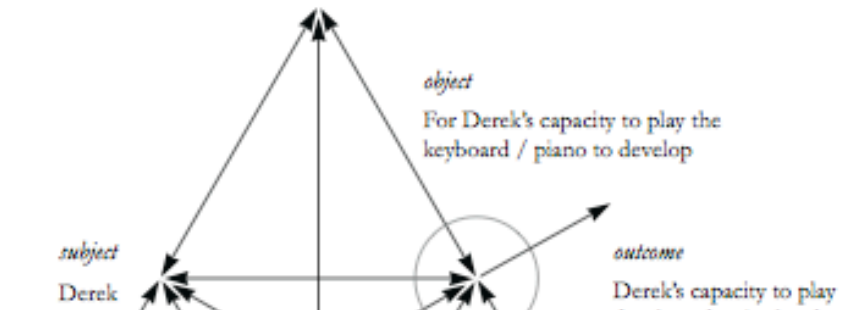

Derex's capacity to piay

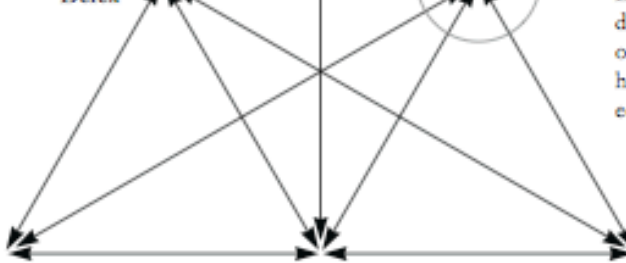

rales, atounptions, expectations and driver

comosivity

Family

- There remain no formal rules of Derek's engagement with music, although the music he hears and reproduces is structured in a highly rule-bound way

- When they realise that he can play people's assumptions about Derek change radically - though no-one understands how be is able to do what he does

- Gradually, expectations grow that

Derek will be able to play on demand

Derek becomes aware of these

expectations and is motivated by

the positive response his playing engenders

and expectations of those around him he develops a highly eccentrie technique 
Figure 4: The activity system pertaining to Derek's musical life, 21-66 months

\section{Stage 3 (from 66 months)}

Derek and $\mathrm{AO}$ develop an unconventional though effective 'teacher-pupil' relationship that enables Derek to learn through verbal guidance and physical intervention

mediating artefiacts

- Derek's piano

- Weekly sessions with $\mathrm{AO}$

- Teaching tapes, made by $\mathrm{AO}$

- Daily sessions with Nanng, using the tapes,

as reinforcement

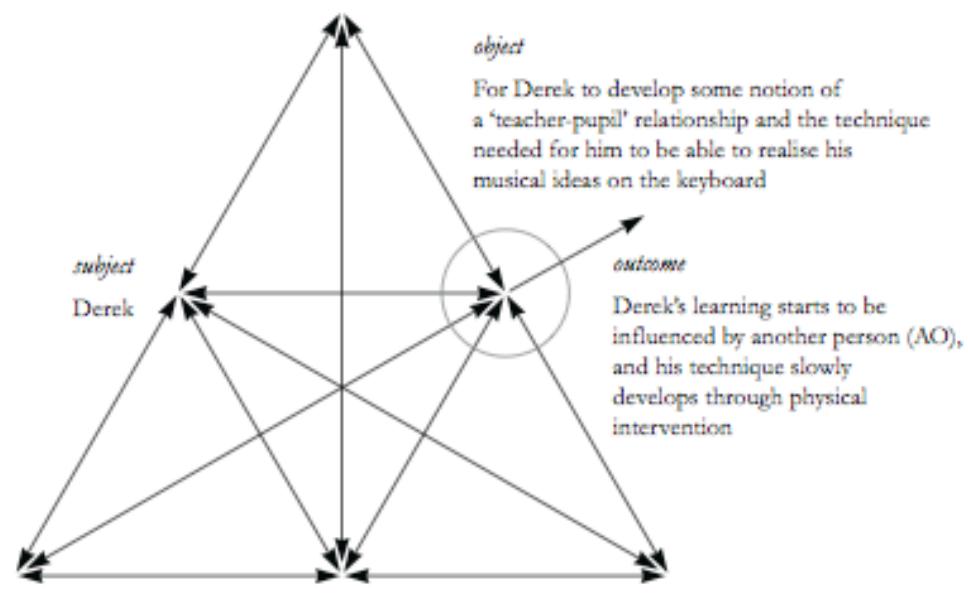

miles, atsonptions, expectafions and diviver

somessitity

division of labour

- AO tries to inculate the ground rules

$\mathrm{AO}$

of a teacher-pupil relationship by

Nanny

- AO has sessions with Derek, at first

playing 'copy' games with Derel.

allowing him to take the lead, showing

in sound, showing him that

him that a non-verbal discourse in

sound is possible

potentially this is a two-way thing that

discourse is possible through music

- Derek increasingly allows $A O$ to take the lead in that discourse

- Derek comes to enjoy the discourse, and comes to appreciate its reciprocity: accepting the influence of another through sound and realising that he can influence someone else

- Derek has enough awareness of the rules of teacher-pupil interaction to allow $\mathrm{AO}$ to guide him technically (necessary since Derek cannot see or understand what is required)

- AO physically guides Derek in the accuisition of technique through excercises, scales and arpeggios; something that continues for many years

- Derek accepts and comes to expect the guidance from $\mathrm{AO}$

- Nanny continues to support between sessions 
Figure 5

Classical and other-than-classical-musicians' mean scores for categories of musical activities (extra-curricular: listening to music from own and outside of own genre, acquiring general musical knowledge, engaging in professional conversations, networking; acquiring practical skills: practicing alone, practicing with others, taking lessons, solo and group performance, listening to music from own genre; music for fun: playing for fun alone or with other; solo work: mental rehearsal, giving lessons, solo performance).

Reproduced from A. Creech, I. Papageorgi, C. Duffy, F. Morton, L. Haddon, J. Potter, C. de Bezenac, T. Whyton, E. Himonides and G.F. Welch, Investigating musical performance: commonality and diversity amongst classical and other-than-classical musicians. Music Education Research, 10(2), 223 (C) 2008, Taylor and Francis.

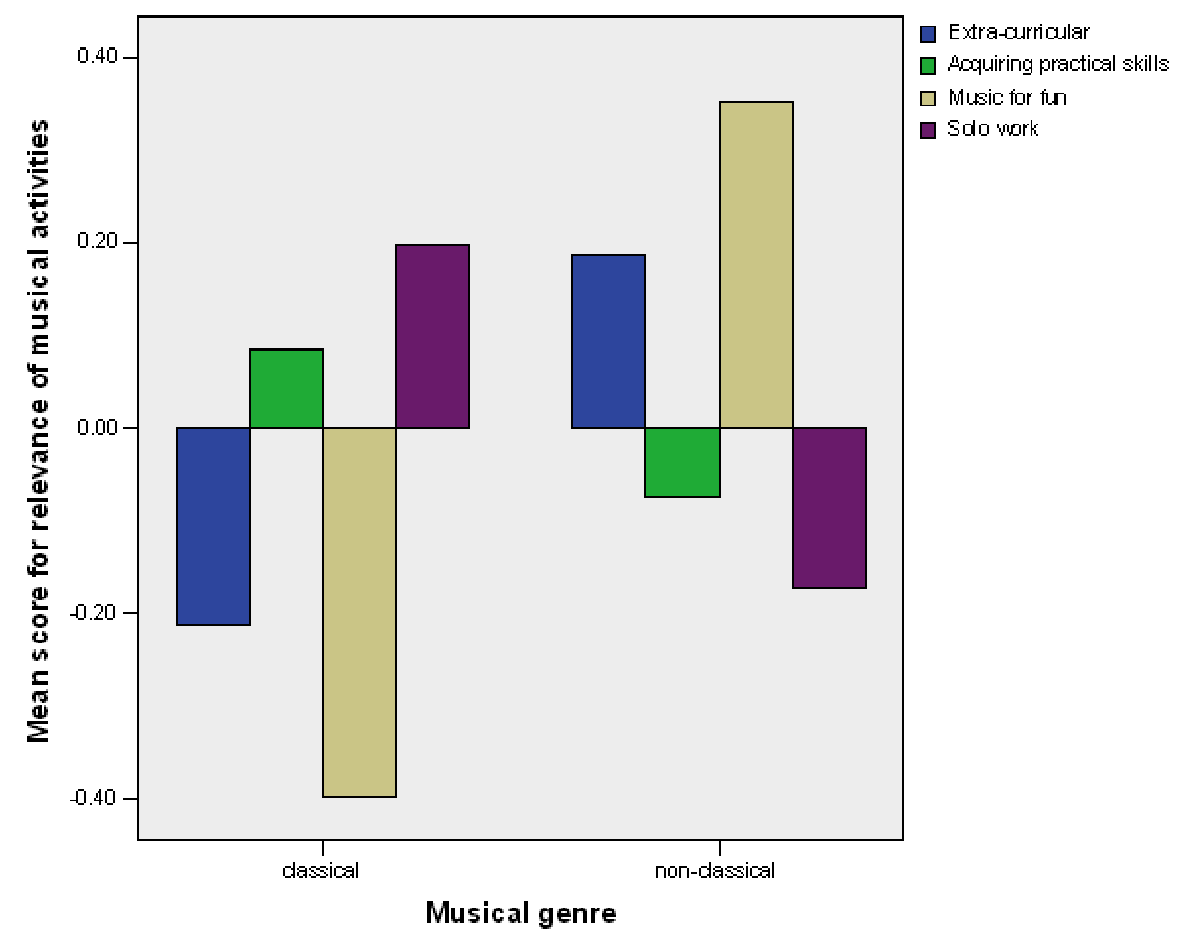




\section{Figure 6}

An example of the activity system that frames the development of the novice (female) cathedral chorister.

Reproduced from G.F. Welch, Addressing the multifaceted nature of music education: an activity theory research perspective. Research Studies in Music Education, 28(1), 29 ( 2007, SEMPRE, with permission.

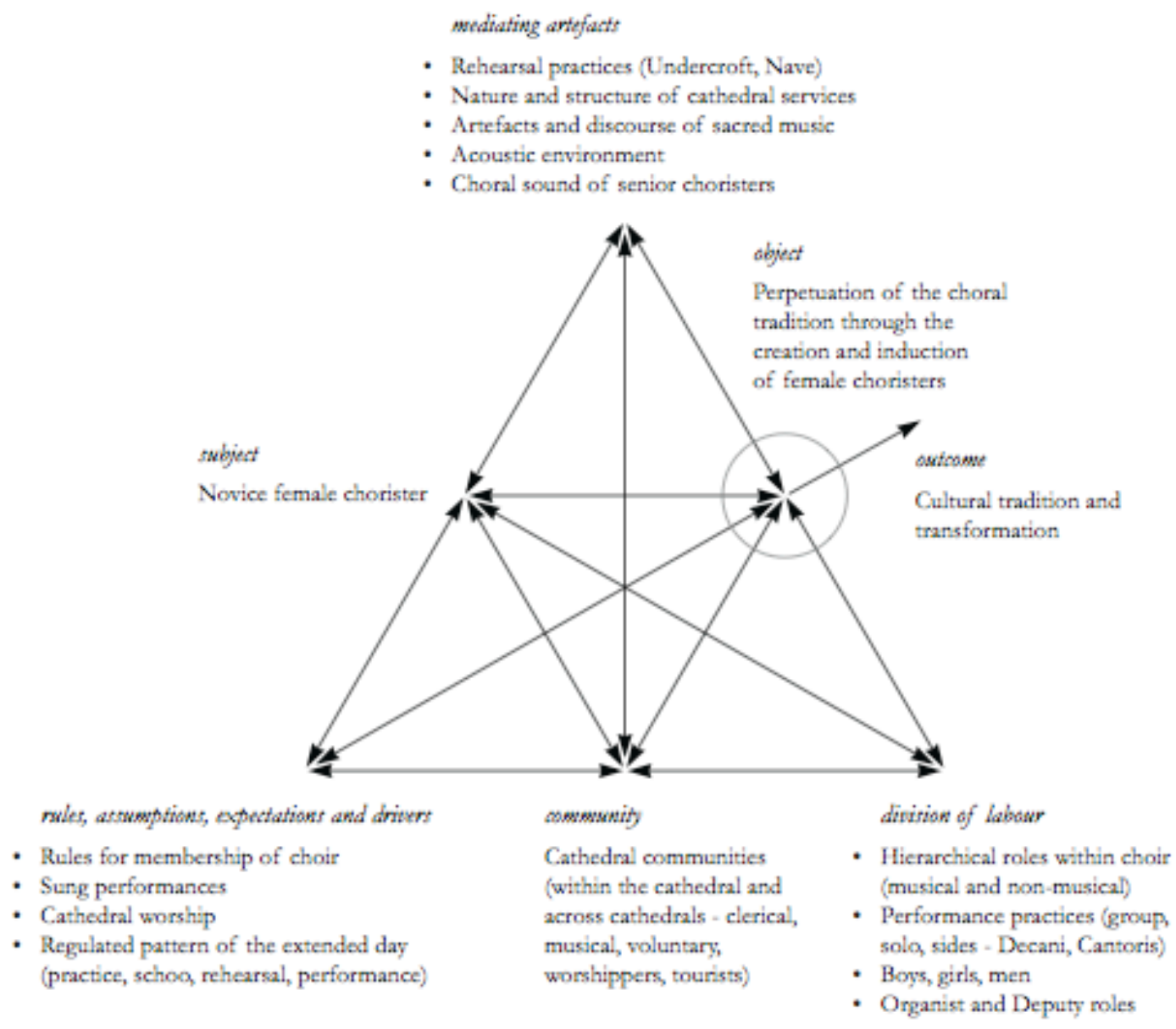


Table 1

Pupils' Self-Identified Grouping Related to Classroom Music in Year 9 (age 13+) of

\section{Lower Secondary School}

\begin{tabular}{|l|l|}
\hline Pupil Identity Related to School Music & \multicolumn{1}{|c|}{ Example Key Characteristics } \\
\hline Traditional Western musician & $\begin{array}{l}\text { Strong engagement with all music; good family support; } \\
\text { Successful experience of formal learning of an instrument } \\
\text { Peer group status as a "musician" }\end{array}$ \\
\hline Western nonmusician & $\begin{array}{l}\text { Strong engagement with music outside school; limited family support } \\
\text { Limited instrumental skill; immediate peer group do not identify with } \\
\text { school music; peer group recognition as a "non"musician }\end{array}$ \\
\hline "Alternative Western musician" & $\begin{array}{l}\text { Strong engagement with all music; family support } \\
\text { Informally/self-taught instrumental skills } \\
\text { School music seen as irrelevant; peer group status as a "musician" }\end{array}$ \\
\hline $\begin{array}{l}\text { WDisengaged traditional } \\
\text { Western musician" }\end{array}$ & $\begin{array}{l}\text { Strong engagement with music outside school } \\
\text { Formally taught instrumental skills, family support variable } \\
\text { Peer group do not identify with school music } \\
\text { Music curriculum seen as a "threat" to musician status within } \\
\text { peer group }\end{array}$ \\
\hline $\begin{array}{l}\text { Strong engagement with music outside school; } \\
\text { Informally or self-taught instrumental skills; family support limited }\end{array}$ \\
\hline $\begin{array}{l}\text { Peer group share counter culture of musical identity } \\
\text { Musician" status threatened by lack of success }\end{array}$
\end{tabular}

${ }^{1}$ The Office for Standards in Education (Ofsted) assesses the quality of music teaching on behalf of the government. This is a non-ministerial government department that reports directly to the UK Parliament. Ofsted is headed by a senior civil servant and is required to inspect and report on the quality of education in schools, initial teacher education and, more recently, child minding, child day care, children's centres, and children's social care. 